\title{
Iron Supplementation of Exclusively Breast-Fed Infants
}

\section{James Friel*}

Department of Human Nutritional Sciences, University of Manitoba, Canada

Breast-fed infants who follow the WHO recommendations to exclusively breast feed for 6 months [1] may be at risk for iron deficiency. Recommendations are clear and state that no solids only vitamin D as a supplement should be introduced before 6 months of age. Prior to these recommendations solids could be introduced between 4 and 6 months and was the norm in many countries. Solids were introduced to meet increasing needs for energy and iron due to rapid growth of the full term infant.

The first food for infants in North America has traditionally been iron fortified rice cereal [2]. Rice being the least allergenic grain and iron as stores are depleting. Solids were often started as early as 2 months of age with a concurrent decline in breastfeeding and increased intake of humanized infant formulas that were iron fortified. Therefore iron intakes were sufficient to prevent the majority of infants from iron deficiency (ID) and iron deficiency anemia (IDA) both with potential adverse effects including irreversible cognitive decline.

With the extended time for exclusive breastfeeding to 6 months of age introduction of solids was pushed to a later date and introduced new problems. Firstly iron stores would further deplete as there is very little iron in mother's milk and rapidly depleting postnatal stores would further be stressed. It is noteworthy that at no other time in the life cycle nor for any other nutrient do we allow stores to run out before repleting them. This is particularly of concern for iron as every cell in the body requires iron and cell growth is rapid in infancy. Secondly what iron rich foods should be introduced as the first solid? Cereal is the traditional food but by 6 months infants appear to be sufficiently developed to digest and assimilate meat [3]. However this raises public health concerns as infants usually eat meat late in infancy $[2,4]$ and adult recommendations usually include provisos against consumption of certain meats for example, preserved with nitrates. Certainly fruits vegetables and most grains do not contain enough iron to make them viable first foods.

In order to deal with these issues the American Academy of Pediatrics [5] recently revised their recommendations for exclusively breast fed infants. They state: "it is recommended that exclusively breastfed term infants receive an iron supplementation of $1 \mathrm{mg} / \mathrm{kg}$ per day, starting at 4 months of age and continued until appropriate iron-containing complementary foods have been introduced...." The Academy based their bold new recommendations on all the available evidence and particularly an article from Friel et al. [6] where iron supplementation of exclusively breast-fed infants in the early months improved iron status, psychomotor scores and visual acuity. This new recommendation provoked a strong response from major thought leaders [7] and from within the broader AAP committee itself [8]. Why in the face of such strong opposition and at risk of polarizing the breast-feeding community did the AAP make such a radical move?

This editor cannot speak for the AAP committee but can offer some rationale. Firstly: the amount of iron required to meet requirements for body growth cannot be met by newborn stores and the iron content of human milk. Fomon [9] has done the calculations for required absorbable iron and it is clear some source of exogenous iron is needed in early infancy. Secondly: iron ID and IDA are not desirable states as the consequences appear to be severe and irreversible if encountered in early infancy [10]. Thirdly: by extending the time of exclusive breastfeeding to 6 months the risk that new food options will not contain sufficient iron is real [2].

Arguments against iron supplementation include: implicit undermining of breast feeding; potential adverse effectsincluding growth faltering in iron replete individuals; implementing a broad public health policy that only benefits selected individuals. The rationale that human milk is "perfect as is" flies in the face of vitamin D supplementation. It has become slowly accepted that vitamin D supplements are needed, why not iron? Growth deficit has been reported in iron supplemented infants [11] but the data is not consistent [12]. What is consistent is the psychomotor advantage provided to iron supplemented infants [13]. The concern about universal supplementation is warranted because there is no agreed upon screening tool to tell which infants are at risk for ID/IDA [14]. The data suggests that low birth-weight infants, aboriginal infants, infants from low socioeconomic backgrounds and multiple pregnancies are at risk and should receive iron supplements while breastfeeding. Routine blood tests are invasive and costly and there are no certain guidelines to guide us on who should be tested. It appears that the AAP committee concluded in a risk/benefit analysis that supplementation was warranted.

Both sides of the debate are filled with passionate oratory and sincerity. We are all concerned with both too little and too much iron intake and the wellbeing of the newborn. Clearly (to use a trite expression) more research is needed, particularly a repeat of the Friel et al. [5] study. Monitoring of anemia rates in breast-fed infants who receive the new AAP recommended doses would also help. Finding objective criteria that clearly define at risk individuals is probably the most realistic and accomplishable goal for current researchers.

\section{References}

1. World Health Organization 2008 Indicators for assessing infant and young child feeding practices. Geneva: World Health Organization.

2. Friel JK, Hanning RM, Isaak CA, Prowse D, Miller AC (2010) Canadian Infants nutrient intakes from complementary foods during the first year of life. BMC Pediatr 10: 43-54.

3. Krebs NF, Westcott JE, Butler N, Robinson C, Bell M, et al. (2006) Meat as a first complementary food for breastfed infants: feasibility and impact on zinc intake and status. J Pediatr Gastroenterol Nutr 42: 207-214.

4. Devaney B, Ziegler P, Pac S, Karwe V, Barr SI (2004) Nutrient intakes of infants and toddlers. J Am Diet Assoc 104: S14-21.

5. Baker RD, Greer FR, Committee on Nutrition American Academy of Pediatrics (2010) Diagnosis and prevention of iron deficiency and iron-deficiency anemia in infants and young children (0-3 years of age). Pediatrics 126: 1040-1050.

6. Friel JK, Aziz K, Andrews WL, Harding SV, Courage ML, et al. (2003) A double-

*Corresponding author: James Friel, Professor, Department of Human Nutritiona Sciences, University of Manitoba, Canada, Tel: (204) 474-8682; Fax: (204) 4747552; E-mail: frielj@cc.umanitoba.ca

Received February 10, 2012; Accepted February 10, 2012; Published February 12, 2012

Citation: Friel J (2012) Iron Supplementation of Exclusively Breast-Fed Infants. Vitam Trace Elem 1:e108

Copyright: (c) 2012 Friel J. This is an open-access article distributed under the terms of the Creative Commons Attribution License, which permits unrestricted use, distribution, and reproduction in any medium, provided the original author and source are credited. 
masked, randomized control trial of iron supplementation in early infancy in healthy term breast-fed infants. J Pediatr 143: 582-586.

7. Hernell O, Lönnerdal B (2011) Recommendations on iron questioned Pediatrics 127: e1099-1101.

8. AAP Section on Breastfeeding, Schanler RJ; Executive Committee, FeldmanWinter L, Landers S, et al. (2011) Concerns with early universal iron supplementation of breastfeeding infants. Pediatrics 127: e1097.

9. Fomon SJ (1993) Nutrition of normal infants Mosby, p253-255.

10. Carter RC, Jacobson JL, Burden MJ, Harmony-Sivan R, Dodge NC, et al (2010) Iron deficiency anemia and cognitive function in infancy. Pediatrics 126 : e427-434.
11. Dewey KG, Domellöf M, Cohen RJ, Landa Rivera L, Hernell O, et al. (2002) Iron supplementation affects growth and morbidity of breast-fed infants: results of a randomized trial in Sweden and Honduras. J Nutr 132: 3249-3255.

12. Fischer Walker CL, Baqui AH, Ahmed S, Zama K, El Arifeen S, et al. (2009) Low-dose weekly supplementation of iron and/or zinc does not affect growth among Bangladeshi infants. Eur J Clin Nutr 63: 87-92.

13. Szajewska H, Ruszczynski M, Chmielewska A (2010) Effects of iron supplementation in nonanemic pregnant women, infants, and young children on the mental performance and psychomotor development of children: a systematic review of randomized controlled trials. Am J Clin Nutr 91: 16841690.

14. Lozoff B (2003) Do breast-fed babies benefit from iron before 6 months? J Pediatr 143: 554-556. 